\title{
Gnathostomiasis: an emerging infectious disease relevant to all dermatologists*
}

\author{
Francisco Bravo ${ }^{1,2}$
}

Bernardo Gontijo ${ }^{3,4}$

DOI: http://dx.doi.org/10.1590/abd1806-4841.20187498

\begin{abstract}
Gnathostomiasis is a parasitic infection caused by the third larval stage of nematodes of the genus Gnathostoma. The disease is endemic in some countries around the world. In the American continent, the majority of cases is concentrated in Mexico, Ecuador, and Peru. However, due to increasing traveling either at the intercontinental or intracontinental level, the disease is seen each time more frequently in tourists. Furthermore, countries, such as Brazil, that have never been considered endemic are reporting autochthonous cases. The disease usually presents as a deep-seated or slightly superficial migratory nodule in patients with history of eating raw fish, in the form of ceviche, sushi, or sashimi. Along with the clinical presentation, diagnostic criteria include either blood or tissue eosinophilia. In most instances, these criteria are enough for the attending physician to institute therapy. Chances of finding the parasite are low, unless the biopsy is taken from a very specific area that develops after antiparasitic treatment is started. The potential of other organ involvement with more serious consequences should always be kept in mind.
\end{abstract}

Keywords: Communicable diseases, emerging; Gnathostoma; Gnathostomiasis; Helminthiasis; Nematode infections; Travelers' health

\section{INTRODUCTION}

Gnathostomiasis is a parasitic infection that results from the migration of the third larval stage (L3) of nematodes of the Gnathostoma genus through human tissues. Most commonly, this migration takes place in the skin and subcutaneous tissues. The disease is mainly seen in areas of the world that are considered endemic, such as Southeast Asia, Japan, and Latin America, but has been increasingly observed in travelers returning to non-endemic areas, such as the United States or Europe. The infection is acquired through the consumption of freshwater fish or eel, either raw or marinated in lemon juice, in the form of various popular traditional delicacies, such as sushi, sashimi, or ceviche. The disease has received multiple names, depending on the geographic area where it occurs: tuao chid in Japan, Yangtze River edema and Shanghai rheumatism in China, and nodular migratory panniculitis in Ecuador.

\begin{abstract}
An increasing number of reports of autochthonous cases from non-endemic countries (e.g., Brazil and Colombia) suggest that the distribution of the parasite in nature may be wider than expected. Under this current situation, dermatologists around the world, and especially in Latin America, should be aware of the clinical manifestations, since the skin is the most common organ involved in the form of a migratory nodular dermatitis or panniculitis.
\end{abstract}

\section{HISTORY}

Gnathostoma was first described by Richard Owen in 1836 in the stomach of a young tiger that died at the London Zoo. In 1872, Fedchenko identified the parasite in the stomach of a pig and named it G. hispidum. Levinson described the first human case in Thailand in the year 1889, in a woman infected with multiple lar-

\footnotetext{
Received on 03.08.2017.

Approved by the Advisory Board and accepted for publication on 27.09.2017

* Work performed at the Universidad Peruana Cayetano Heredia - Lima, Peru and Universidade Federal de Minas Gerais (UFMG) - Belo Horizonte (MG), Brazil. Financial support: None.

Conflict of interests: None.

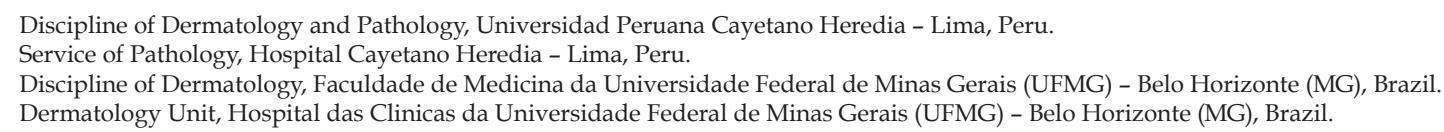


vae. The next case took many years to be reported, as late as 1934 . Prommas and Dangsavand described the complete life cycle of the parasite in $1937 .^{1,2}$

In America, the first human cases of gnathostomiasis were reported by Pelaez \& Perez Reyes in Mexico, in 1970. ${ }^{3}$ Ollague, in Ecuador, in 1985, wrote extensively about the occurrence of the disease in humans and animals in the Guayas estuary. ${ }^{4}$ The first series in Peru was described by Costa et al., in 2001. ${ }^{5}$ Dani et al. reported the first imported case in Brazil, in 20096, and Vargas et al. described the first autochthonous case in Rio, in 2012 . $^{7}$

\section{EPIDEMIOLOGY}

The highest incidence is observed in Japan and some of the Southeast Asia countries, such as Thailand, Cambodia, Laos, Myanmar, Indonesia, Philippines, Malaysia, and Vietnam. ${ }^{1,8}$ Other cases have been reported in China, India, and Sri Lanka. The disease has also been diagnosed in patients after traveling to Africa. ${ }^{9}$

In the American continent, the largest number of cases is from Mexico, but gnathostomiasis is also found in Guatemala, Ecuador, and Peru. An intriguing epidemiological aspect is that whereas in most countries the disease affects predominantly individuals of low socioeconomic classes, in Peru, most patients reside and consume their ceviche in high-class neighborhoods. ${ }^{10}$ In addition, an unexplained issue is how gnathostomiasis can be seen in Peru. The disorder has been so far exclusively associated with fresh or brackish water fish; however, virtually all ceviche consumed in Peru is prepared with saltwater fish. The pending identification of the fish species associated with the disease in Peru will contribute to the better understanding of the epidemiology and risk factors.

In developed countries, the disease is mainly described in travelers. ${ }^{11-14}$ However, some autochthonous cases have been reported in the US (Scott Norton, personal communication).

Imported and autochthonous cases have been recently reported in Brazil ${ }^{7,15}$, Colombia, ${ }^{16}$ and Korea. ${ }^{17}$ In the specific case of Brazil, one patient developed gnathostomiasis after traveling to Peru, while the patient reported by Vargas was infected after consuming local raw peacock bass (Cichla spp) during a fishing trip to the state of Tocantins. ${ }^{7}$ One has to bear in mind that little is known about the occurrence of Gnathostoma species in the wildlife around the world. The importation of swamp eels from Asia to the United States resulted in the contamination of local species of freshwater eels raised in the US, increasing the possibility of autochthonous cases in a country that had never been endemic. ${ }^{11}$

\section{PATHOGENESIS}

Gnathostoma is a nematode (cylindrical worm) that belongs to the order Spiruria. Thirteen species of Gnathostoma have been described, of which only five have been associated with human disease. G. spinigerum is the most commonly reported and is usually isolated from cats and dogs in Asia. Other species associated with human disease include G. hispidum (found in domestic pigs in Europe, Asia, and Australia), G. doloresi, G. nipponicum, and, more recently, G. binucleatum, which seems to be the predominant species in cases reported in Mexico and Ecuador.
The life cycle requires three hosts: a freshwater copepod; several species of fresh or brackish water fish and other aquatic animals; and a definitive host for the adult forms. The final hosts are most commonly felines and canines, either domestic or wild.

The adult male and female worms, measuring from 13 to 55 $\mathrm{mm}$ in length, nest in the gastric mucosa of a definitive host, such as cats and dogs, and occasionally tigers and leopards. Eggs are expulsed in the feces and reach a freshwater stream. After a seven-day incubation period, eggs hatch the first larval (L1) stage. As such, larvae are ingested by a copepod or water flea of the genus Cyclops, in which they evolve into a second stage (L2). The copepod is then ingested by other animals, such as fish, eels, frogs, birds, or reptiles. Once inside these second hosts, the larvae migrate to the muscle tissues, maturing into the infective third larval stage (L3). The larval development goes on through the ingestion by other predators, ranging from smaller animals (fish) to larger ones (birds, larger fish), until the parasite reaches again the definitive host to complete the cycle. Ollague postulates that the cycle is completed, at least in the Guayaquil area, when the local fishermen feed their domestic animals (cats and dogs) with decaying fish, not suitable for human consumption but contaminated with L3 larvae. ${ }^{4}$ These domestic animals are the definitive hosts and harbor the adult forms that will reach maturity in six months. Their egg-containing feces end up in the river and estuary water to restart the life cycle. Humans acquire the disease by ingesting raw fish containing the L3 larvae, and most infections are caused by one single larva. Other animals listed as potential sources of infection include snakes, frogs, and chicken. Exceptionally, the infection may be due to the consumption of contaminated water or handling contaminated meat with subsequent direct invasion of the larva through the skin.

The infective larva measures up to $12.5 \mathrm{~mm}$ long and $1.2 \mathrm{~mm}$ wide, with a whitish, pink color. The head pole has a round mouth, with hooks and a grinding apparatus that is reminiscent of the front part of a tunnel drill machine. The cycle in humans starts with an enteric phase, with the worm perforating the gastric or intestinal mucosa to reach the peritoneal cavity (sometimes inducing so much pain that it simulates an acute abdomen) or migrating through the liver. The larva can potentially perforate the pleura and the lung, producing pleurodynia, hemoptysis, and pneumothorax. Most likely, the larva moves towards the skin, wandering either in the deep fat tissue level or at a more superficial dermal level. This migration occurs in bouts, with periods of quiescence with no detectable larval movement, resulting in complete disappearance of symptoms. Eosinophilia reaches its peak during the invasive abdominal phase and during the active migration. The larva can move as fast as $1 \mathrm{~cm}$ per hour.

Although the cutaneous symptoms of the disease wax and wane and may follow a chronic course, more severe complications arise when deeper structures are invaded, such as the lung, mediastinum, eye, or, in the worst scenario, the central nervous system (CNS). The parasite causes damages not only by direct trauma to tissues but also by secretion of compounds, such as analogs of acetylcholine, a hyaluronidase-containing spreading factor, proteolytic enzymes, and hemolytic substances, besides the inflammation caused by the intense tissue eosinophilia. 


\section{CLINICAL MANIFESTATIONS}

\section{Cutaneous gnathostomiasis}

About three to four weeks after the ingestion of the larva, the patient notices a nodular, lumpy area or an ill-defined, edematous, erythematous area of infiltration in any part of the skin (Figure 1). These lesions can be itchy or painful. The skin feels either slightly infiltrated or even hard on palpation; no systemic symptoms, such as fever or malaise, are present. The disease may be easily mistaken for an inflammatory process, such as a deep-seated boil or a ruptured cyst. A trivial first medical evaluation by a non-dermatologist or someone with no knowledge of the disease results in an erroneous diagnosis of a bacterial infection, with the subsequent administration of oral antibiotics. As this first episode of swelling tends to heal spontaneously after 7 to 14 days, the apparent clinical response to antibiotic therapy will reassure patients and physicians of the assumed bacterial origin. However, a few weeks or months later, the same symptoms relapse but in a nearby location or even in more distant sites. Common locations for the migratory nodule include the abdomen and the chest, but the initial presentation can be anywhere, from the extremities (as far as the dorsum of the hand) to the head and neck area and even the scalp. These latter locations should be considered high-risk areas due to the potential involvement of the eyes or CNS. The migratory pattern of the recurrent nodule is perhaps the most important clue for the diagnosis of gnathostomiasis. The nodule is always a solitary lesion, but evidence of the migration can be seen in the adjacent areas. Gnathostomiasis is unlikely if the patient presents with simultaneous, inflammatory nodules in multiple locations.

Clinical features that may help the dermatologist to raise the diagnosis of gnathostomiasis include the elongated form of the initial infiltration (revealing a local migratory phenomenon) or the peau d'orange surface of the erythematous area, rather uncommon findings in other inflammatory processes, such as boils or bacterial pyodermas (Figure 2).

Other forms described include a very superficial presentation identical to what is seen in the creeping eruption of cutaneous larva migrans (CLM), and the most common presentation in our

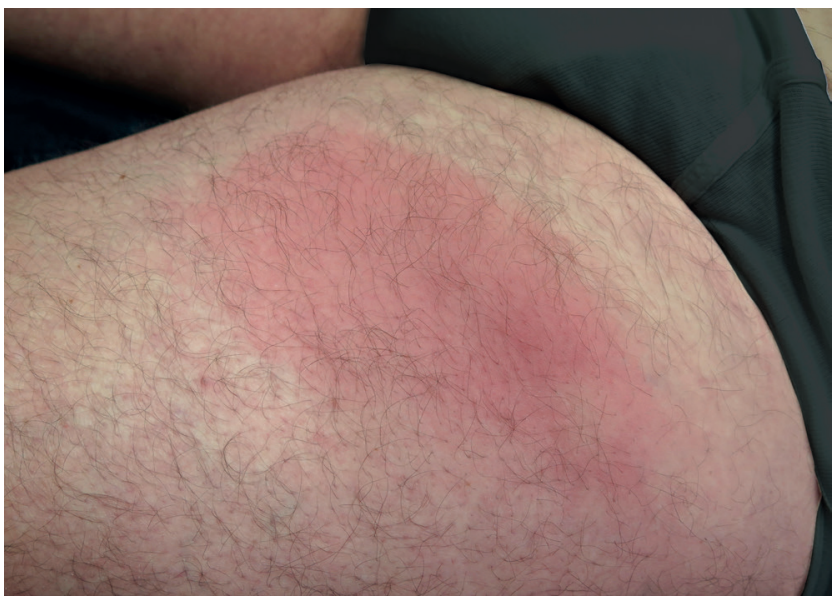

FIGURE 1: The classical presentation: migratory panniculitis experience: a mixed form, with a nodule adjacent to a superficial tract (Figures 3 and 4). The creeping eruption-like form of gnathostomiasis can be differentiated from CLM due to the location (thoracic and breast locations are uncommon in CLM) or the absence or epidemiological data in favor of CLM, such as walking barefoot in beaches or sandy areas.

A very interesting presentation is the so-called pseudo-furuncular type. As described by multiple authors, either spontaneously or, more commonly, a few days after therapy, the clinical lesion evolves from a large nodular or ill-defined infiltrated area to a tiny papule or even a pustule (Figure 5).,18,19 This phenomenon represents the upward migration of the parasite towards the surface of the skin. The confirmation of this phenomenon is the finding of the parasite either attached or embedded in the tissue when the papule is punched out or contained in the pustule on top of the papule. Spontaneous exit of the parasite is rarely reported.

Recurrent migratory nodules may occur up to 10 to 12 years after infection, with prolonged asymptomatic periods in which the larva remains in a resting, hibernating state. ${ }^{1} \mathrm{~A}$ nodular lesion may persist fixed in one location after therapy. When such an area is biopsied, a viable larva can be found, most likely hibernating.

\section{Visceral gnathostomiasis}

Different internal organs may be impaired, and the same intermittent pattern of symptomatology seen in the cutaneous forms applies to the visceral involvement. One case followed by one of the authors (FB) presented initially only with abdominal pain, followed by retroperitoneal pain, hematuria, symptoms of meningitis, and, lastly, evidence of migration of the larva in the skin and subcutaneous tissue of the lower back. When the larva penetrates the thoracic cavity, clinical manifestations include cough, pleuritic pain, hemoptysis, collapse of the lung, pleural effusion, and pneumothorax. Pulmonary consolidation can be observed in $X$ ray. This visceral manifestation is associated with high peripheral eosinophilia and may end up with the expectoration of the larva.

The involvement of the abdominal cavity, most common in the initial period, may result in symptoms of acute abdomen,

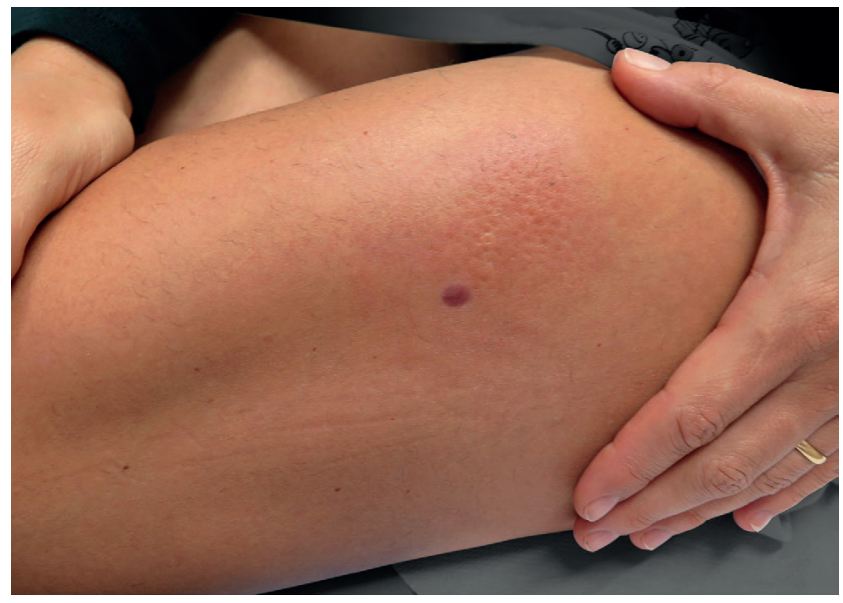

FigurE 2: Sometimes the surface of the erythematous area acquires the peau d'orange aspect 
mimicking appendicitis, acute cholecystitis, or gut perforation. The lack of findings in the surgical exploration or the eosinophilic infiltration of abdominal organs, such as the liver, should alert the clinician about the possibility of acute intraabdominal gnathostomiasis, especially if associated with high eosinophilia and dietary risk factors.

The passing of the parasite near the ureter may result in hematuria. Vaginitis, cervicitis, balanitis, and hematospermia have been reported, as well. ${ }^{1}$

Eye involvement is not so rare in endemic areas and is particularly seen in India. ${ }^{11}$ It has also been recently reported in the state of Amazonas, Brazil, reinforcing the idea of new areas of disease prevalence caused by unidentified species of Gnathostoma. ${ }^{20}$ The parasite invasion favors the anterior chamber, and the eye is the only organ where the larva can be seen directly, in vivo. Ocular involvement manifests clinically as intense pain in the ocular globe, as well as a decreased visual capacity in up to $40 \%$ of cases. ${ }^{21}$ The parasite can produce uveitis, iritis, intraocular hemorrhage, glaucoma, and even retinal scarring and detachment due to a less common invasion of the vitreous. Ocular involvement is rarely associated with peripheral eosinophilia., ${ }^{1,22}$

CNS involvement is associated with the highest mortality, ranging from $8 \%$ to $25 \%$. Before albendazole and ivermectin were available, up to $30 \%$ of the patients experienced prolonged sequelae. ${ }^{1}$ Most commonly, it presents as myelitis and radiculopathy, but meningitis and subdural hemorrhage may also occur. Pain, either radicular or as headache, is interpreted as the passage of the parasite near nerve roots; the pain may last for up to five days and is frequently followed by variable motor deficit, from weakness to a complete paraparesis. Cerebral involvement is associated with altered consciousness and coma but not with mental confusion. The recurrent pattern of the disease can also be seen in cases of CNS involvement by Gnathostoma. The most catastrophic event is the perforation of a vascular structure, resulting in massive subarachnoid

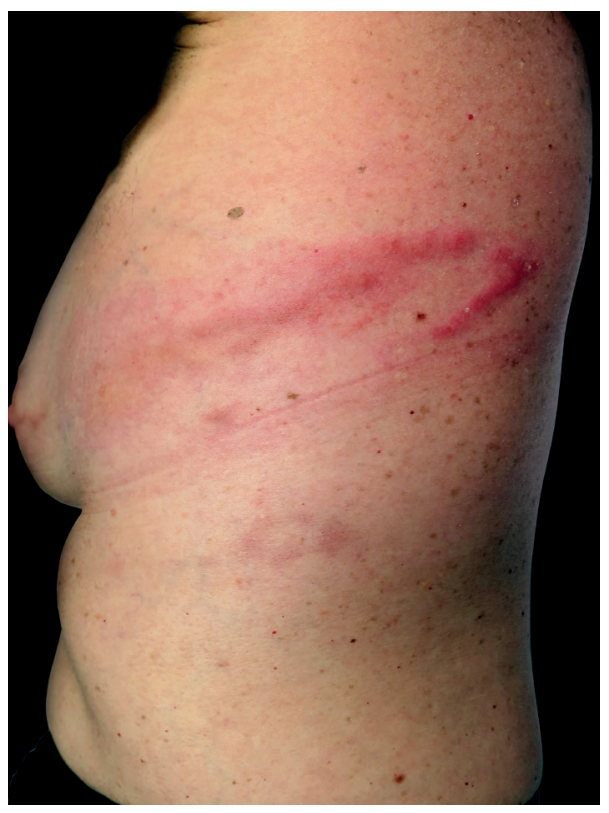

Figure 3: A more superficial lesion may mimic cutaneous larva migrans hemorrhage, a complication particularly seen in Thailand. The main differential diagnosis of CNS gnathostomiasis is the infection by $\mathrm{An}$ giostrongylus sp., a disease mostly seen in Southeast Asia. ${ }^{1}$

\section{DIAGNOSIS}

The possibility of gnathostomiasis should be raised in a patient with a migratory skin lesion ranging from a nodule to an ill-defined mass, either inflammatory (most commonly) or non-inflammatory, in the absence of systemic symptoms, and with a history of consumption of fresh or brackish water fish, either raw or marinated in lemon juice. History of traveling to endemic areas is
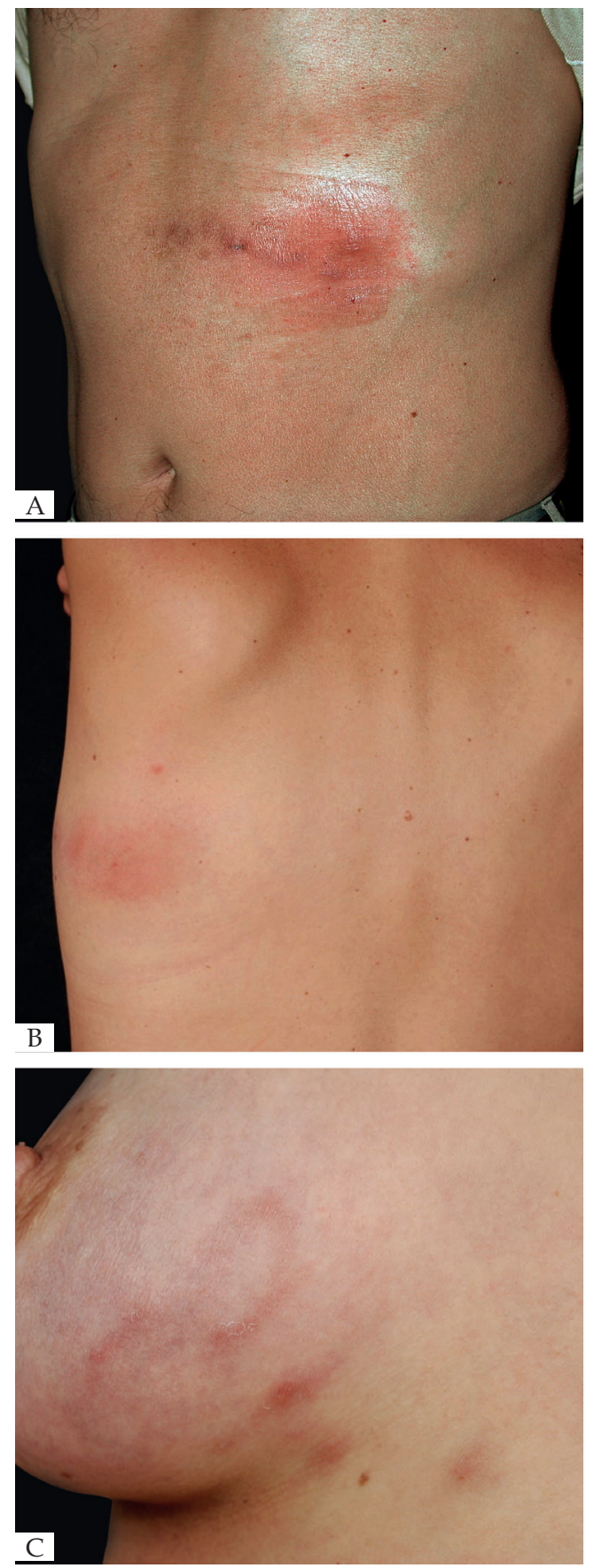

Figure 4:

Two patients with the mixed form: a combination of deep-seated panniculitis and cutaneous larva migrans-like lesions. A - a patient from Peru. B e C - a patient from Brazil who acquired gnathostomiasis by eating ceviche while vacationing in Peru 
very important, but taking into account the increasing number of autochthonous cases, the absence of such information does not rule out the diagnosis. Special attention should be placed in obtaining the history of consumption of freshwater fish in any rural areas of South America.

Gnathostomiasis should also be considered in the differential diagnosis of CLM, especially when lesions are located in areas of the body not commonly associated with CLM (such as the breast and other covered areas), and in those patients in whom the superficial creeping eruption has a deeper, palpable, contiguous component.

Dermoscopy may allow the visualization of the parasite, especially in cases of superficial, pseudo-furuncular lesions. ${ }^{23}$

Mild to severe peripheral eosinophilia is present in $50 \%$ to $70 \%$ of the cases, but normal eosinophil levels do not exclude the diagnosis. Eye involvement is rarely associated with eosinophilia due to the avascular nature of the anterior chamber and to a decreased cellular response. ${ }^{22}$

If eosinophilia is absent, a skin biopsy is quite helpful. The amount of eosinophils is variable, and although not pathognomon-

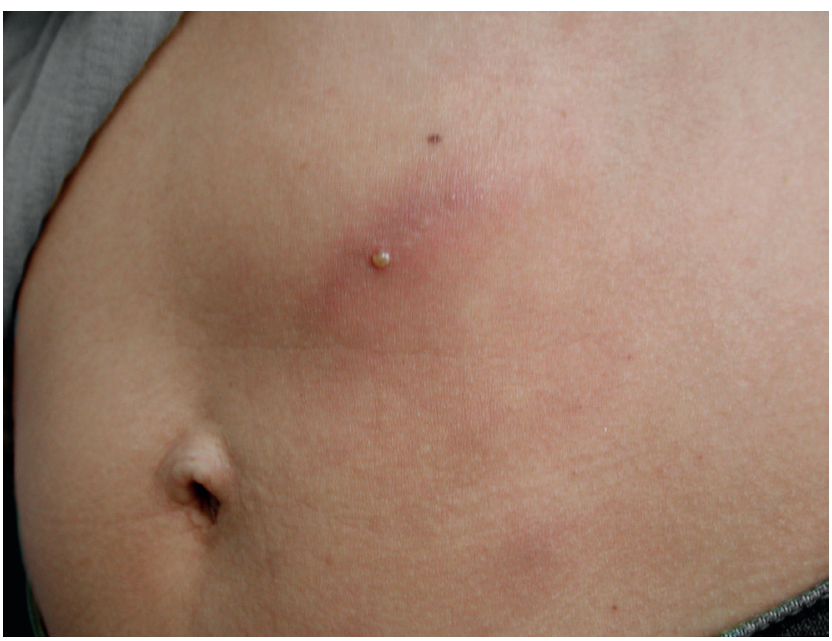

Figure 5: A larva-containing pustule following therapy

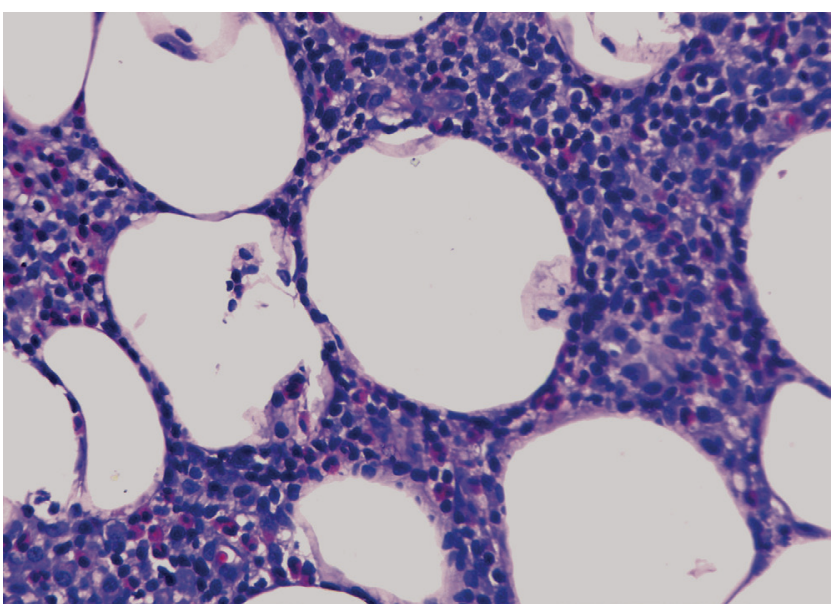

Figure 6: Classical eosinophilic panniculitis. (Hematoxylin \& eosin, $\mathrm{X} 20)$ ic, their presence in the subcutaneous tissue (eosinophilic panniculitis) is highly characteristic (Figure 6). The infiltrate, however, may be limited to the dermis. Flame figures can be seen in gnathostomiasis and, as such, should not be considered characteristic of Wells syndrome only (eosinophilic cellulitis) (Figure 7).

Epidermal changes are rarely observed but correlate with the severity of the underlying infiltrate of eosinophils. The chances of detecting the larva are very low, but they increase in the pseudo-furuncular form that develops immediately after starting specific therapy (Figure 8). The larva usually lies in the dermis and is easily differentiated from the worm of CLM (smaller larva, burrow at the epidermal level) and the Strongyloides larva (may travel in the deep dermis but is quite smaller than Gnathostoma). If the larva can be extracted, is expulsed spontaneously, or is attached to the inferior

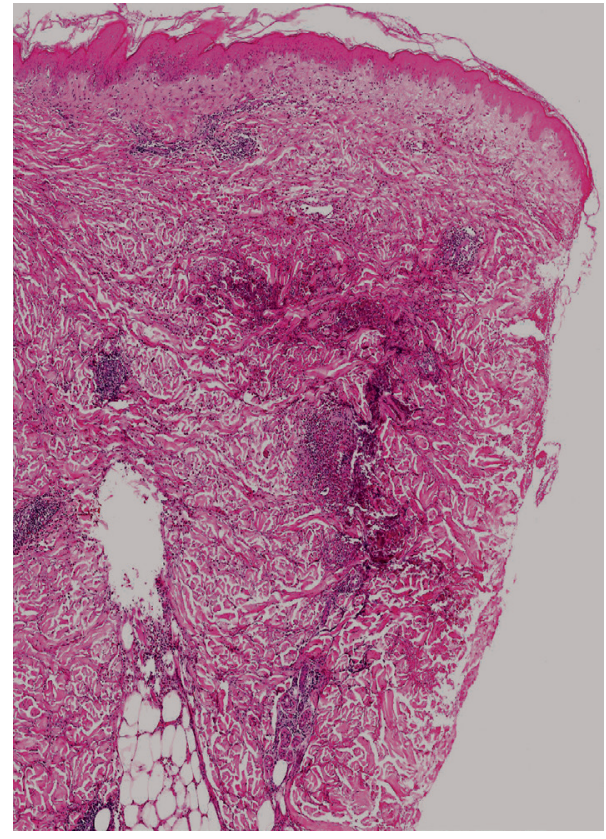

Figure 7:

Flame figures are not uncommon in gnathostomiasis, as a result of the intense infiltration by eosinophils. (Hematoxylin \& eosin, X4)

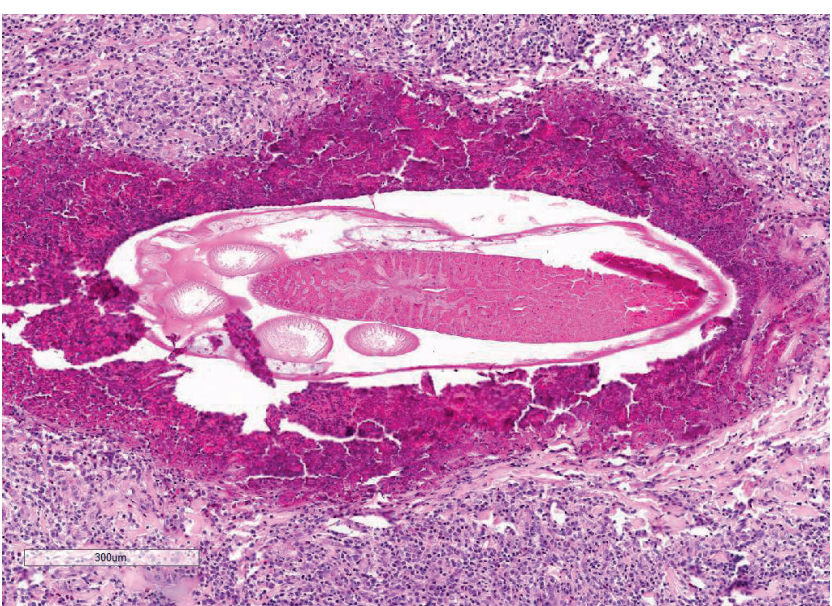

FIGURE 8: The anterior segment of the worm: the cephalic pole is on the left and the muscular esophagus from the center to the right. This is not a complete larva, but just a tangential cut through the anterior half. No intestine is present. (Hematoxylin \& eosin, X4) 
surface of the biopsy, it can be mounted on a slide and observed directly under the microscope (Figure 9).

In the experience of one of the authors (FB), the induction of the parasite migration towards the surface of the lesion usually takes place one to five days after specific therapy is started (either albendazole or ivermectin). The patient is advised to return to the clinic promptly if this phenomenon occurs. If the clinical exam shows either the evolution into a single papule or a distinct papule on top of the plaque, a biopsy is taken to include the whole new lesion (Figure 10). The chances of finding the larva are higher than in a biopsy randomly taken from any portion of the initial lesion. ${ }^{19}$ A reconstruction of the anatomy of the larva made from biopsies of at least six different patients is shown in figure 11.

The differential diagnosis of a migratory nodular lesion showing a large parasite in a biopsy should also include sparganosis, a disorder caused by the tertiary larval state of cestodes (flat worms) of the genus Spirometra. The causative agent has a life cycle quite similar to the Gnathostoma species involved in gnathostomiasis. The history of consumption of raw freshwater fish may also be obtained in sparganosis cases, but it is more commonly associated with drinking water from rivers or ponds in the wilderness or eating wild frogs or reptiles. The most common clinical presentation is a fixed nodule, but a migratory pattern of deep-seated eosinophilic panniculitis may be seen. Sparganosis has been described in South America, especially in Paraguay and Peru. Most cases come from the rural areas of Paraguay and the Amazon region of Peru. The diagnosis is straightforward if the parasite is seen. As a nematode (cylindrical worm), Gnathostoma appears round in biopsy tangential sections. Spirometra is a cestode (flat worm) much bigger than Gnathostoma, and as opposed to Gnathostoma, the larva (sparganum) does not have an intestinal tract but rather a mesenchyme with channels and calcified bodies.

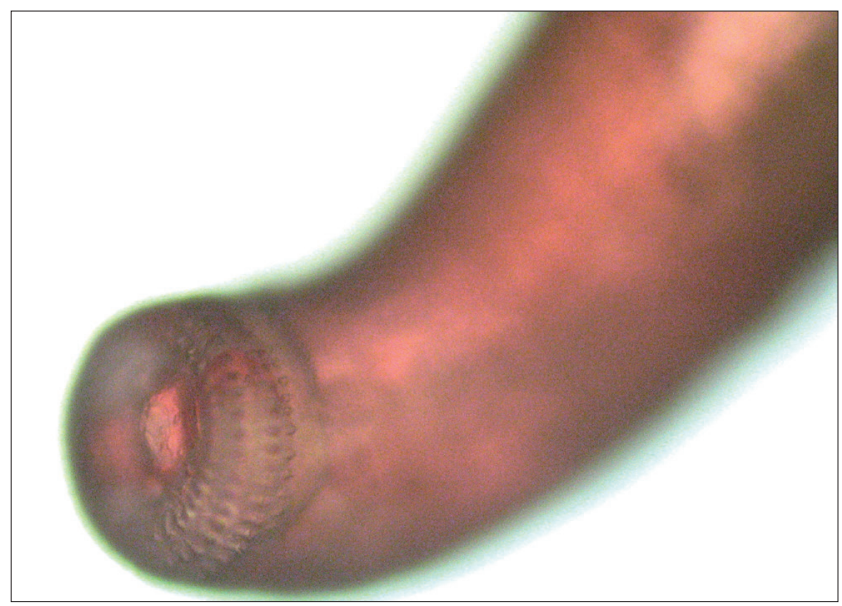

Figure 9: A larva attached to the inferior portion of a punch biopsy specimen from a papule that developed after therapy. It was carefully extracted, mounted on a slide, and examined under the microscope. The mouth of the parasite and the perioral spines are evident, mimicking a tunnel drill machine
Serological tests for the diagnosis of gnathostomiasis include an enzyme-linked immunosorbent assay (ELISA) for L3 immunoglobulin $\mathrm{G}$ antibody, with low sensitivity and high crossreactivity with other nematode species. A western blot assay directed against a crude preparation of G. spinigerum has been developed in Asia and Europe; the detection of a $24-\mathrm{kDa}$ L3 antigen band is considered diagnostic of gnathostomiasis. However, the test is only available at research institutions, such as Mahidol University in Thailand and the Swiss Tropical and Public Health Institute of Basel, Switzerland.

A Western blot assay directed against G. binucleatum L3 antigen, using a larval extract isolated from contaminated fish in the Guayas area, Ecuador, has been recently developed. ${ }^{24}$ G. binucleatum is the species most likely responsible for the Mexican and Ecuadorian cases. The results from this report show that serum from South American patients positively reacts against the antigen but not to G. spinigerum antigen, confirming that most cases in this region are due to G. binucleatum. Ribosomal DNA (rDNA) sequencing has also been used as a tool for classification and phylogenetic analysis of gnathostomiasis in the American continent. , 25 $^{25}$

Neuroimaging findings should not be considered diagnostic but may help to establish the magnitude of the CNS involvement. MRI has some advantage over CT scan and may be useful to distinguish gnathostomiasis from angyostrongyloidiasis. ${ }^{26}$

\section{EVOLUTION AND PROGNOSIS}

If left untreated, the cutaneous and visceral manifestations of gnathostomiasis may persist for prolonged periods, up to 12 years. Even when the prognosis is favorable, such as in cases with only cutaneous impairment, the risk of complications increases with specific involvement of certain organs, such as the eye and the CNS. It is our understanding that patients with migratory panniculitis in the head and neck region should be closely monitored, since they are more prone to develop such complications.

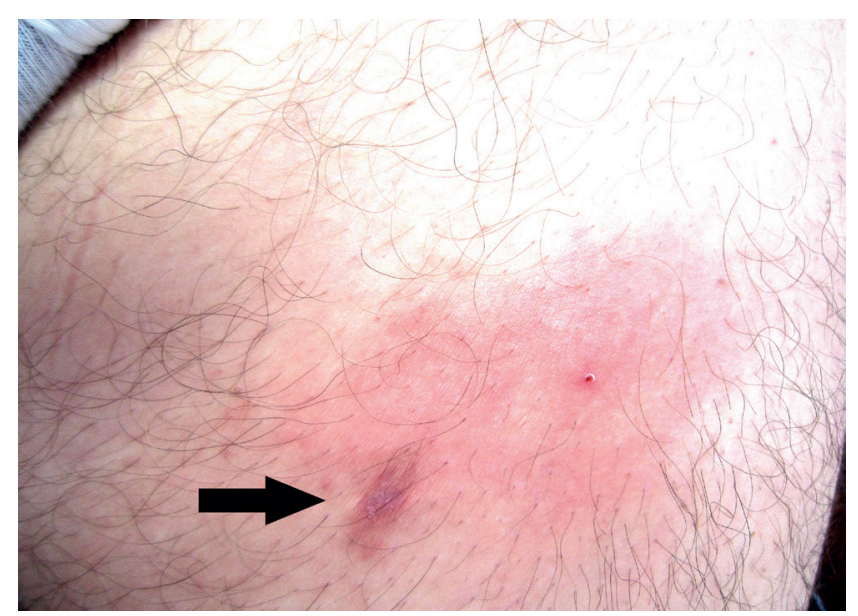

Figure 10: The same patient showed on Figure 1 developed an elongated papule (arrow) at the border of the original plaque five days after the administration of oral albendazole. The new lesion was excised and the parasite was found (Figure $11 \mathrm{D}$ ) 


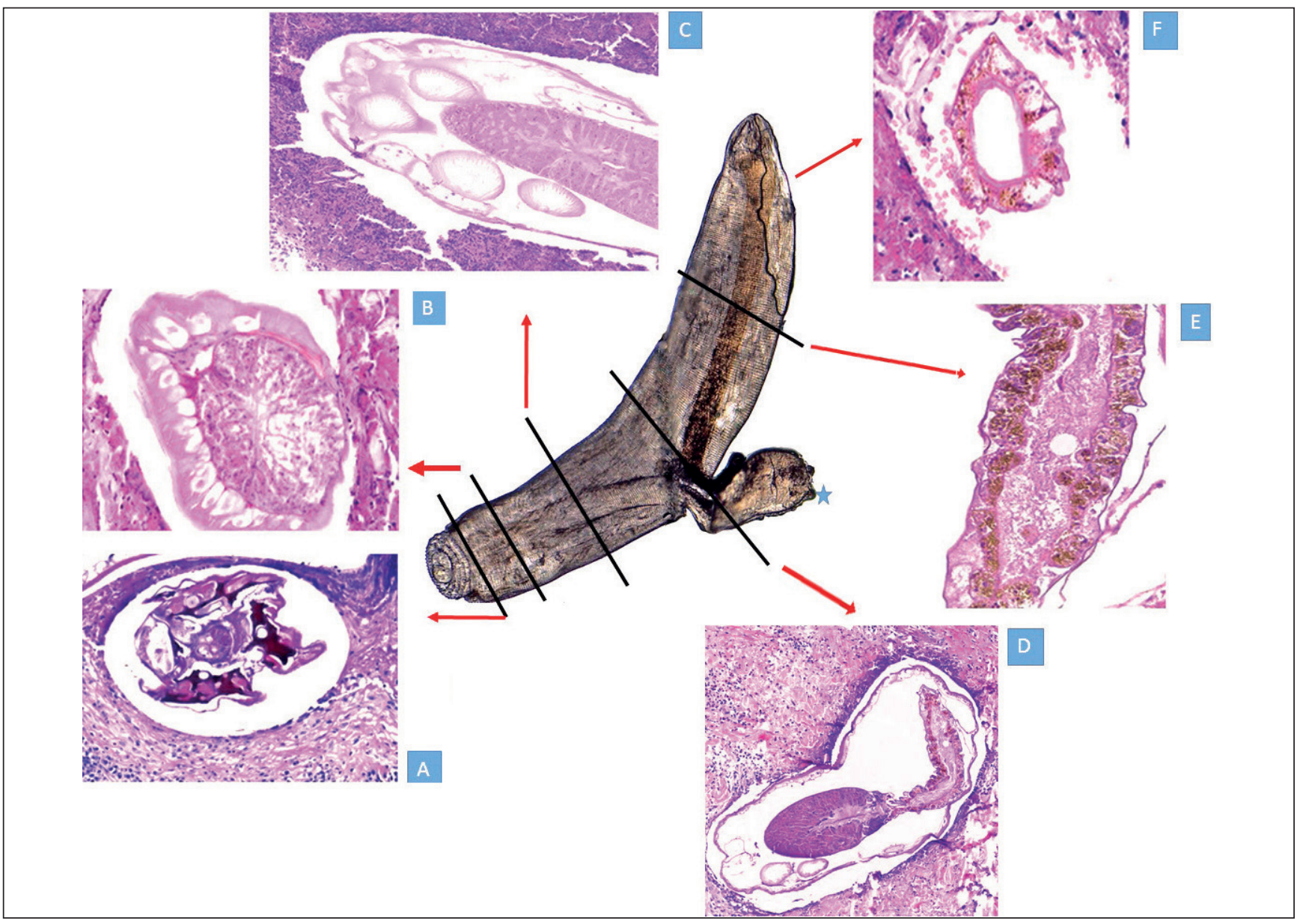

FIGURE 11: This is a sectional reconstruction of the parasite from biopsies of six different patients after inducing the pseudoforuncular form with specific therapy. The whole parasite seen at the center was obtained alive from a pustule that developed after therapy. The larva was mounted on mineral oil and seen with a conventional microscope. The area marked with * is a traumatic, artefactual herniation of the intestinal tract induced while mounting.

$11 \mathrm{~A}$ - Section of the mouth apparatus

$11 \mathrm{~B}$ - The head bulb and the esophagus

11C - Cervical papillae surrounding the esophagus

11D - The union between distal esophagus and proximal intestine, with its intestinal pigmented epithelium. In the lower left corner, some sections of papillae are seen

$11 E$ - Distal pigmented intestine

\section{TREATMENT}

Current therapy of gnathostomiasis includes oral albendazole, $400 \mathrm{mg}$ bid for 21 days, with an efficacy over $90 \%$. The alternative regimen is a single dose of ivermectin, $0.2 \mathrm{mg} / \mathrm{kg}$, that may be repeated after seven days.

Some patients may experience recurrence of the disease after an apparently successful initial therapy. In some series, the cure rate after a first initial dose may be as low as $40 \%{ }^{27}$ Relapses can be managed with the same initial drug or, with better results in our experience, with albendazole and ivermectin given simultaneously. Sometimes, local recurrence that manifests only as transient redness or itching in an area previously affected, but without migration, can be managed conservatively with antihistamine, especially if eosinophilia is absent. However, new migration should be considered as evidence of a living parasite, requiring a new cycle of treatment. The option of simultaneous administration of albendazole and ivermectin can be also considered in cases where the migration occurs in the head and neck region.

CNS involvement can cause cerebral edema and requires the assistance of a neurologist. In such instances, a course of oral steroids before the administration of the antiparasitic drug is advisable. This situation is analogous to the one observed in neural cysticercosis. 


\section{PREVENTION}

Avoidance of raw fish ingestion, the most relevant preventive measure, may be difficult to achieve, given the preference of locals and travelers for such a popular alimentary habit. Natives may believe that marinating the fish eliminates the larva, but the L3 larva does survive easily in lemon juice for up to five days. Quick freezing of fish employed in the preparation of sushi, sashimi, or ceviche will kill the larva, but this procedure may not be feasible or necessarily enforced. Homemade preparations of such delicacies also increase the risk of developing the disease. $]$

\section{REFERENCES}

1. Herman JS, Chiodini PL. Gnathostomiasis, another emerging imported disease. Clin Microbiol Rev. 2009;22:484-92.

2. Camacho L. Gnathostomiasis, el caso de Mexico. Epidemiologia en Breve. 2011;1:1.

3. Facmed.unam.mx [Internet]. Berrueta TU. Gnathostomosis o Gnathostomiasis. Recursos en parasitologia UNAM. [cited 2017 Jun 8]. Available from: http:// www.facmed.unam.mx/deptos/microbiologia/parasitologia/gnathosmosis.html

4. Ollague W. Gnathostomiasis, nueva enfermedad en Ecuador y América del sur [monografia] Guayaquil, Ecuador: Colegio Ibero Latino Americano de Dermatología. Instituto Ecuatoriano de Seguridad Social IESS; 1985.

5. Costa H, Bravo F, Valdez L, Scavino Y, Sordo C, Magill F, et al. Paniculitis nodular migratoria eosinofílica en el Perú (gnathostomiasis humana).Folia Dermatol Peru. 2001;12:21-35.

6. Dani CM, Mota KF, Sanchotene PV, Maceira JP, Maia CP. Gnathostomiasis in Brazil: case report. An Bras Dermatol. 2009;84:400-4.

7. Vargas TJ, Kahler S, Dib C, Cavaliere MB, Jeunon-Sousa MA. Autochthonous gnathostomiasis, Brazil. Emerg Infect Dis. 2012;18:2087-9.

8. Xuan Le T, Hoa PT Le, Dekumyoy P, Hoan NH, Khuong LH, Van TTH, et al . Gnathostoma infections in South Vietnam. Southeast Asian J Trop Med Public Health. 2004;35:97-9.

9. Hale DC, Blumberg L, Frean J. Case report: gnathostomiasis in two travelers to Zambia. Am J Trop Med Hyg. 2003;68:707-9.

10. Alvarez P, Bravo F, Morales A. Gnathostomiais, experience in private practice in Lima, Peru. Folia Dermatol Peru. 2011;22:67-74.

11. Diaz JH. Gnathostomiasis: An emerging infection of raw fish consumers in Gnathostoma nematode-endemic and nonendemic countries. J Travel Med. 2015;22:318-24

12. Moore DA, McCroddan J, Dekumyoy P, Chiodini PL. Gnathostomiasis: an emerging imported disease. Emerg Infect Dis. 2003;9:647-50.

13. Ménard A, Dos Santos G, Dekumyoy P, Ranque S, Delmont J, Danis M, et al. Imported cutaneous gnathostomiasis: report of five cases. Trans R Soc Trop Med Hyg. 2003;97:200-2.

14. Jarell AD, Dans MJ, Elston DM, Mathison BA, Ruben BS. Gnathostomiasis in a patient who frequently consumes sushi. Am J Dermatopathol. 2011;33:e91-3.

15. Cornaglia J, Jean M, Bertrand K, Aumaître H, Roy M, Nickel B. Gnathostomiasis in Brazil: an emerging disease with a challenging diagnosis. J Travel Med. 2016;30;24:1-4.

16. Jurado LF, Palacios DM, López R, Baldión M, Matijasevic E. Cutaneous Gnathostomiasis, first confirmed case in Colombia. Biomedica. 2015;35:462-70.

17. Kim JH, Lim H, Hwang YS, Kim TY, Han EM, Shin EH, et al. Gnathostoma spinigerum infection in the upper lip of a Korean woman: an autochthonous case in Korea. Korean J Parasitol. 2013;51:343-7

18. Tarango Martinez VM, Rojas G,Barba JA. Gnathostomiasis , variedad pseudoforunculosa. Dermatologia Rev Mex. 2011;55:84-94.

19. Laga AC, Lezcano C, Ramos C, Costa H, Chian C, Salinas C, et al. Cutaneous gnathostomiasis: report of 6 cases with emphasis on histopathological demonstration of the larva. J Am Acad Dermatol. $2013 ; 68: 301-5$.

20. Chaves CM, Chaves C, Zoroquiain P, Belfort R Jr, Burnier MN Jr. Ocular Gnathostomiasis in Brazil: A case report. Ocul Oncol Pathol. 2016;2:194-6.

21. Lamothe-Argumedo R, Osorio-Saravia D. Estado actual de la Gnathostomiasis en Mexico. Anales Inst Biol Univ Nac Auton Mexico, Ser Zool. 1998;69:23-37.

22. Barua P, Hazarika NK, Barua N, Barua CK, Choudhury B. Gnathostomiasis of the anterior chamber. Indian J Med Microbiol. 2007;25:276-8.

23. Úraga E, Garcés S, Úraga MV, Reyes A, Garcés JC. Dermoscopic features of cutaneous gnathostomiasis. Int J Dermatol. 2015;54:986-8.

24. Neumayr A, Ollague J, Bravo F, Gotuzzo E, Jimenez P, Norton SA, et al. Crossreactivity pattern of Asian and American human gnathostomiasis in Western Blot assays using crude antigens prepared from Gnathostoma spinigerum and Gnathostoma binucleatum third-stage larvae. Am J Trop Med Hyg. 2016;95:413-6.

25. Almeyda-Artigas RJ, Bargues MD, Mas-Coma S. ITS-2 rDNA sequencing of Gnathostoma species (Nematoda) and elucidation of the species causing human gnathostomiasis in the Americas. J Parasitol. 2000;86:537-44.

26. Kanpittaya J, Sawanyawisuth K, Intapan PM, Khotsri P, Chotmongkol V, Maleewong W. A comparative study of neuroimaging features between human neuro-gnathostomiasis and angiostrongyliasis. Neurol Sci. 2012;33:893-8.

27. Strady C, Dekumyoy P, Clement-Rigolet M, Danis M, Bricaire F, Caumes E. Longterm follow-up of imported gnathostomiasis shows frequent treatment failure. Am J Trop Med Hyg. 2009;80:33-5

How to cite this article: Bravo F, Gontijo B. Gnathostomiasis: an emerging infectious disease relevant to all dermatologists. An Bras Dermatol. 2018;93(2):172-80. 


\section{QUESTIONS}

1. The clinical manifestations of gnathostomiasis are induced by a. a systemic reaction to the presence of the adult form in the intestinal tract.

b. migration of the adult form of Gnathostoma in the skin.

c. migration of the L1 larval stage in the skin.

d. migration of the L3 larval stage in the skin.

2. Regarding Gnathostoma sp., mark the CORRECT statement.

a. All species are pathogenic to humans.

b. They are flatworms.

c. The pathogenic species are G. spinigerum in Asia and G. binucleatum in Latin America.

d. G spinigerum has been implied in cases from Europe, Asia, and Latin America.

3. In most instances, the disease is acquired through

a. the invasion of the gastric and intestinal mucosae by a single larva present in a piece of raw fish.

b. the invasion of the colonic mucosa by multiple larvae in contaminated fish flesh.

c. penetration of multiple larvae in the plantar skin.

d. ingestion of multiple larvae from contaminated water that penetrate the gastric mucosa.

4. Which clinical presentation less likely represents gnathostomiasis?

a. Multiple bilateral hot nodules on both arms.

b. A single hot cutaneous plaque in the epigastric area.

c. A large red, slightly elevated plaque in continuity with a linear CLM-like lesion.

d. A single, ill-defined nodule on the forehead.

5. Regarding visceral involvement, it is CORRECT to state that gnathostomiasis can produce

a. acute abdomen.

b. pneumothorax.

c. hematuria.

d. all of the above.

6. Regarding CNS involvement, it is INCORRECT to state that

a. it is associated with high mortality.

b. myelopathy and radiculopathy are the most common presentation

c. cerebral involvement is commonly associated with mental confusion.

d. cerebral involvement is commonly associated with altered consciousness and coma.
7. Treatment should be instituted

a. only after serologic tests become positive.

b. if the parasite is found in biopsy.

c. after confirmatory imaging with ultrasound or MRI.

$\mathrm{d}$. in the presence of a migratory lesion associated with blood or tissue eosinophilia.

8. Dermoscopy allows the visualization of the parasite in

a. a deep-seated nodule.

b. a pseudofuruncular lesion.

c. all clinical forms.

d. only in the mixed form.

9. The skin biopsy of gnathostomiasis is characterized by

a. few eosinophils.

b. massive infiltration of eosinophils.

c. either dermatitis or panniculitis.

d. All of the above.

10. Which of the following drugs is effective?
a. Albendazole
b. Mebendazole
c. Ivermectin
d. A and C

\begin{tabular}{|c|c|c|c|}
\hline \multicolumn{4}{|c|}{ Answer key } \\
\hline \multicolumn{4}{|c|}{$\begin{array}{l}\text { Mycetomas: an epidemiological, etiological, clinical, labora- } \\
\text { tory and therapeutic review. An Bras Dermatol. 2018;93(1): } \\
\text { 8-18. }\end{array}$} \\
\hline $1-C$ & $6-\mathrm{C}$ & 11-D & $16-\mathrm{C}$ \\
\hline $2-C$ & 7-B & 12-D & $17-\mathrm{C}$ \\
\hline 3-B & $8-C$ & 13-B & 18-A \\
\hline $4-\mathrm{A}$ & 9-D & 14-D & 19-D \\
\hline 5-D & 10-A & 15-B & $20-A$ \\
\hline
\end{tabular}

Papers

Information for all members: The EMC-D questionnaire is now available at the homepage of the Brazilian Annals of Dermatology: www.anaisdedermatologia.org.br. The deadline for completing the questionnaire is 30 days from the date of online publication. 